\title{
Effect of Droplets on Corrosion Resistance of Tantalum Oxide Films Fabricated by PLD
}

\author{
Takanori Hino*, Minoru Nishida**, Takao Araki*** \\ * Environmental Materials Science and Engineering, Niihama National College of Technology, \\ 7-1 Yagumo-chou, Niihama, Ehime 792-0864, Japan \\ E-mail: hino@mat.niihama-nct.ac.jp \\ ** Kochi prefectural industrial technology center, 399-3 Nunoshida-chou, Kochi 781-5101, Japan \\ ${ }^{* * *}$ Toyo Industrial Creative Center, 2151-10 Oh-Join, Niihama, Ehime792-0060, Japan
}

\begin{abstract}
Tantalum oxide films were prepared using pulsed laser deposition without any exchange of the Ta target. As the number of laser shots increased, the density of metal-rich droplets on the film increased and the droplet diameter became larger, leading to an increase in the total surface area of droplets. The corrosion resistance of the films was characterized by potentiostatic testing in a 3.5 mass $\% \mathrm{NaCl}$ solution at $400 \mathrm{mV}$. It was found that the corrosion resistance improved as the $\mathrm{O} / \mathrm{Ta}$ composition ratio approached its stoichiometric value. Corrosion was observed to originate at local surface pits produced by $\mathrm{Cl}^{-1}$ ions. These pits were formed at the boundaries between the film and droplets whose diameters were larger than the film thickness.
\end{abstract}

DOI:10.2961/j1mn.2011.01.0003

Keywords: pulsed laser deposition, tantalum oxide, corrosion resistance, droplet

\section{Introduction}

Due to its high dielectric constant $\left(\varepsilon_{\mathrm{r}}=25\right)$, tantalum oxide is often considered to be the most promising replacement for $\mathrm{SiO}_{2}\left(\varepsilon_{\mathrm{r}}=3.9\right)$ for use in dielectric films in storage capacitors for Gbit-generation dynamic random access memory (DRAM) [1-6]. On the other hand, it is also attractive as a corrosion-resistant coating film [7-11]. Recent trends towards miniaturization of electronics devices and precision equipment, referred to as "nano technology", have placed increasingly stringent restrictions on the acceptable thickness of corrosion resistance films. Tantalum (Ta) is known to have a corrosion resistance similar to platinum $(\mathrm{Pt})$, and is particularly resistant to attack by $\mathrm{Cl}^{-1}$ ions. This is especially true for highly stable Ta-based passivation films formed on surfaces, even though tantalum itself is not a very noble metal.

We have previously reported on the formation of tantalum oxide films by pulsed laser deposition (PLD) using $\mathrm{Ta}_{2} \mathrm{O}_{5}$ and Ta targets in either pure $\mathrm{O}_{2}$ gas or $\mathrm{O}_{2}$ gas with 5 mass $\% \mathrm{O}_{3}$ [12]. Dense flat films with a stoichiometric composition were obtained at an atmospheric gas pressure of $10 \mathrm{~Pa}$, even when different types of targets were used [13]. We have previously shown that both the O/Ta composition ratio and the Ta-O binding state are factors influencing the corrosion resistance of such films [14]. However, one drawback of the PLD process is the formation of metal-rich droplets on the film surface [15-20]. These droplets can accelerate corrosion through the formation of local cells. In this study, the effect of such droplets on the corrosion resistance of tantalum oxide films was investigated.

\section{Experiment procedures}

Tantalum oxide films were produced in a stainless steel vacuum chamber using an ion source. A 99.95 mass\% Ta target was fixed on a holder, which was rotated at $60 \mathrm{rpm}$ to maintain uniformity of the target surface. A stainless steel substrate (SUS304; 18Cr-8Ni) with a mirror finish was set at a distance of $50 \mathrm{~mm}$ from the target. A KrF excimer laser with a wavelength of $248 \mathrm{~nm}$ and a pulse width of $22 \mathrm{~ns}$ was focused on the target at an angle of $45 \mathrm{de}-$ grees.

$\mathrm{O}_{3}(5$ mass $\%)-\mathrm{O}_{2}$ gas or pure $\mathrm{O}_{2}$ gas was introduced into the chamber at a pressure from $10 \mathrm{mPa}$ to $10 \mathrm{~Pa}$. Films were deposited using a laser fluence of $6.4 \mathrm{~J} / \mathrm{cm}^{2}$ and a repetition rate of $10 \mathrm{~Hz}$ without exchange of the target between depositions. Table 1 shows the experimental conditions used in the present study. Film A was deposited using the initially polished target with a laser irradiation of 15000 shots. Film B was subsequently deposited using the same target with a laser irradiation of 30000 shots. This sequence was repeated for the remaining films without any exchange of the target.

Scanning electron microscopy (SEM) and electron probe micro analysis (EPMA) were used to observe the surface of the films and determine their composition.

The corrosion resistance of the films was evaluated by anodic polarization and potentiostatic testing in a 3.5 mass $\% \mathrm{NaCl}$ solution. The reference electrode was a saturated calomel electrode and the counter electrode was a $\mathrm{Pt}$

Table 1 Experimental conditions for PLD.

\begin{tabular}{|c|c|c|c|}
\hline Film & Shot range & Shot number & Thickness $(\mu \mathrm{m})$ \\
\hline A & $0 \sim 15000$ & 15000 & 1.15 \\
\hline B & $15000 \sim 45000$ & 30000 & 2.30 \\
\hline C & $45000 \sim 60000$ & 15000 & 1.20 \\
\hline D & $60000 \sim 900000$ & 30000 & 2.30 \\
\hline E & $90000 \sim 120000$ & 30000 & 2.30 \\
\hline F & $120000 \sim 135000$ & 15000 & 1.20 \\
\hline
\end{tabular}




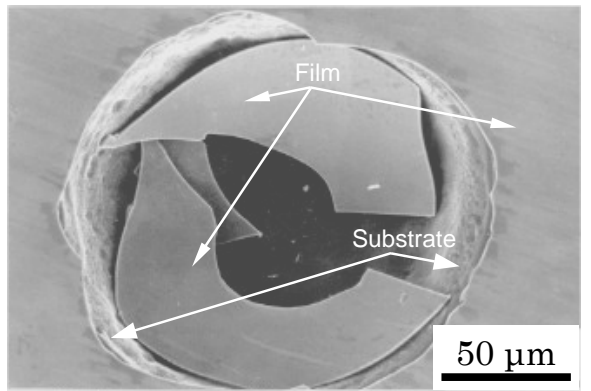

Fig. 1 SEM image of film destroyed by pitting corrosion.

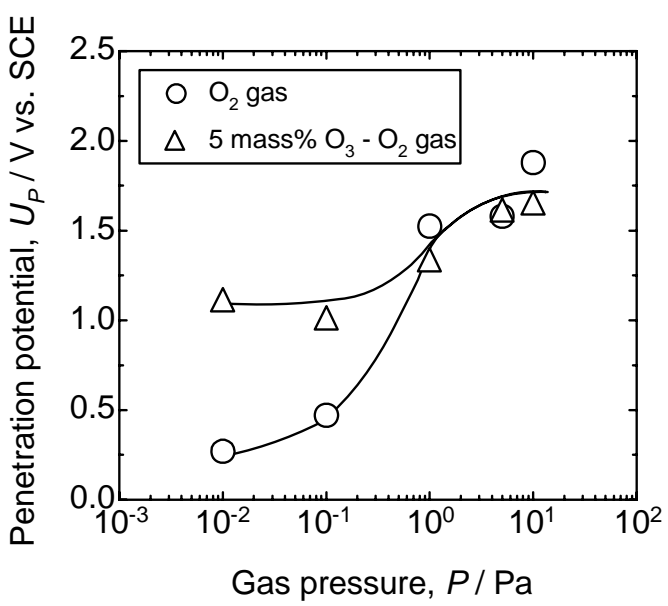

Fig. 2 Relationship between gas pressure and penetration potential.

plate. The solution was deaerated by pure argon gas for 60 min. An epoxy resin was used as an isolator to restrict the sample area to $25 \mathrm{~mm}^{2}$ during the tests. After the films had been soaked in the solution at a static potential for $10 \mathrm{~min}$, the passivation current density was measured at a corrosion potential of $400 \mathrm{mV}$ at room temperature.

\section{Results and discussions}

The penetration potential is defined as the critical potential where the current density suddenly rises and the films are destroyed, as shown in Figure 1. Figure 2 shows the penetration potential of films fabricated in $\mathrm{O}_{2}$ and $\mathrm{O}_{3}(5$ mass $\%)-\mathrm{O}_{2}$ gas. For the case of $\mathrm{O}_{2}$ gas, the penetration potential increases steeply with gas pressure up to $1 \mathrm{~Pa}$. The largest penetration potential is observed at pressures from 5 to $10 \mathrm{~Pa}$, indicating the highest corrosion resistance. For the films produced in $\mathrm{O}_{3}(5$ mass $\%)-\mathrm{O}_{2}$, the penetration potential is almost constant at $1100 \mathrm{mV}$ below $100 \mathrm{mPa}$, and increases slightly to $1400 \mathrm{mV}$ at a pressure of $5 \mathrm{~Pa}$. Thus, the addition of $\mathrm{O}_{3}$ caused a remarkable increase in the corrosion resistance of films deposited at pressures below $1 \mathrm{~Pa}$. This is because the addition of $\mathrm{O}_{3}$ led to the formation of stoichiometric films at lower pressure [14], and such films are naturally more resistant to corrosion. However, as shown in Figure 3, when the corrosion resistance was compared for films of the same composition ratio, there was no advantage in adding $\mathrm{O}_{3}$.

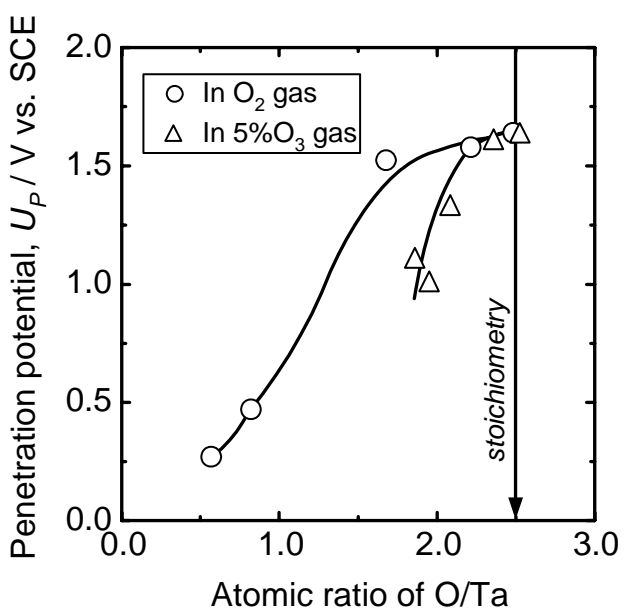

Fig. 3 Effect of $\mathrm{O} / \mathrm{Ta}$ ratio on penetration potential.

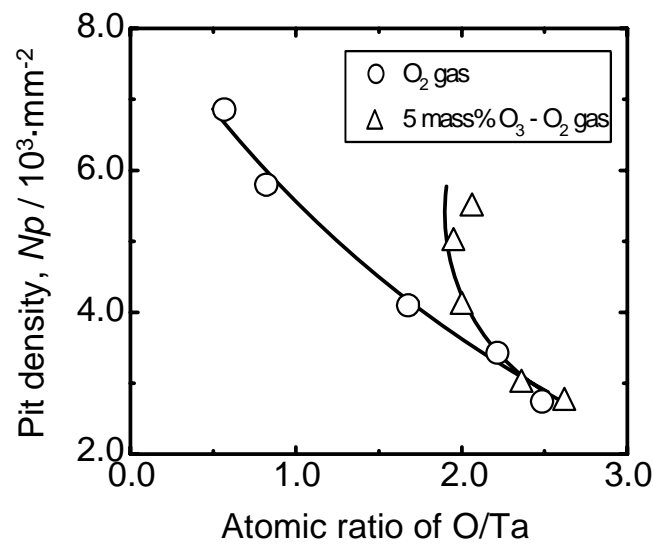

Fig. 4 Relationship between the number of pits and $\mathrm{O} / \mathrm{Ta}$ ratio.

In a previous study, the $\mathrm{O} / \mathrm{Ta}$ composition ratio and Ta-O binding state were found to found to be the main factors affecting the corrosion resistance of tantalum oxide films [13]. However, for deposition at pressures lower than $1 \mathrm{~Pa}$, the formation of metal-rich droplets on the surface must also be taken into consideration. Such droplets are ejected from molten pools on the target surface and can be transported to the substrate due to a reduction in the number of collisions with the ambient gas at lower pressure. The presence of such droplets on the film surface leads to a locally inhomogeneous composition and the formation of cells, which can result in enhanced levels of corrosion.

In order to investigate the corrosion process, the number of pits existing within a surface area of about $10^{-8} \mathrm{~m}^{2}$ $(100 \mu \mathrm{m} \times 100 \mu \mathrm{m})$ was counted after anode polarization testing. This testing was carried out at a potential of 200 $\mathrm{mV}$, which was found to give rise to pitting corrosion of SUS304 steel. Figure 4 shows the effect of the O/Ta ratio on the measured density of corrosion pits. The pit density is seen to decrease with increasing $\mathrm{O} / \mathrm{Ta}$ ratio and exhibits a minimum for stoichiometric conditions. This correlates with the penetration potential results. Corrosion of the film began locally by the generation of pits on the surface by $\mathrm{Cl}^{-1}$ ions during anodic polarization testing, and this continued until the film was destroyed at some critical potential. Thus, the corrosion process is not uniform. 


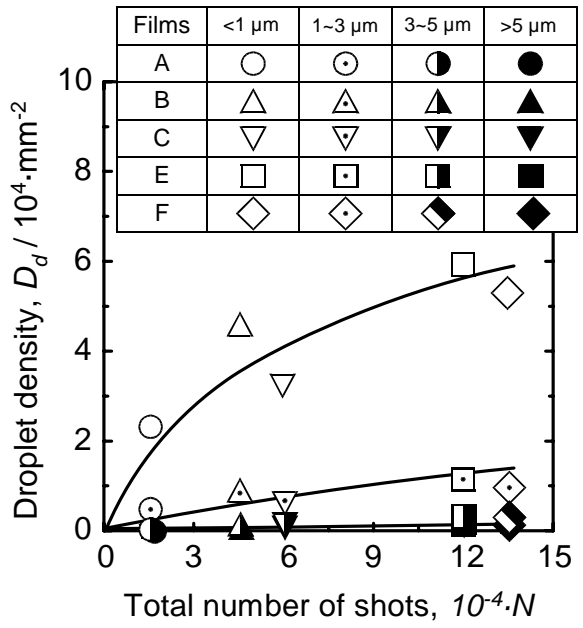

Fig. 5 Relationship between droplet density on the film and total number of laser shots for deposition.

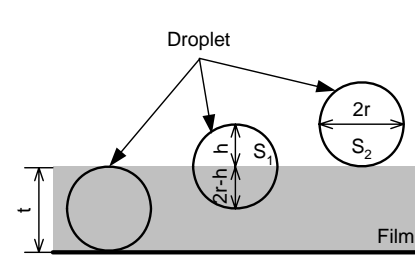

(a) $d \leqq t, 0<h \leqq 2 r$

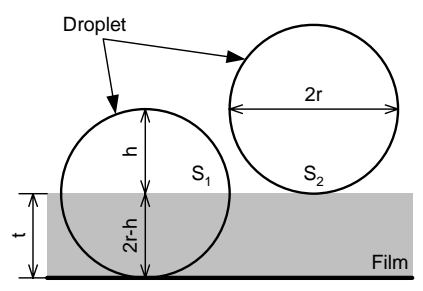

(b) $d>t, r \leqq h \leqq 2 r$
Fig. 6 Illustrations of existence conditions of droplets.

Figure 5 shows the density of droplets of different sizes on the surface of films prepared in $\mathrm{O}_{3}(5$ mass $\%)-\mathrm{O}_{2}$ at a pressure of $10 \mathrm{~Pa}$ under the laser irradiation conditions shown in Table 1. These data were measured from SEM images of an approximately $10^{-2} \mathrm{~mm}^{2}$ region at the center of the films. In addition, the surface of the target was found to exhibit ripples several microns in width and to be very rough following deposition of all films. Thus, many micron-sized droplets solidified after ejection from the top of the ripples, and their sizes were almost identical to those of the droplets on the film surface. Films A, C and F were deposited using 15000 laser shots, and had a thickness of about $1.15 \mu \mathrm{m}$. On the other hand, films B, D and E were deposited using 30000 laser shots, and had a thickness of about $2.3 \mu \mathrm{m}$. From this it was concluded that the deposition rate was constant at $0.08 \mathrm{~nm} /$ pulse. It can be seen from the figure that as the number of pulses increases, the droplet density and average size also increase. In this study, it is shown that the morphology of the target prior to deposition is another factor that affects droplet formation.

From SEM observations, we believe that there are two types of droplets, whose diameters (d) are less than or greater than the film thickness, as illustrated in Figure 6(a) and (b). The droplet surface areas $\mathrm{S}_{1}$ and $\mathrm{S}_{2}$ can be calculated as follows.

Let us consider circular droplet with radius $r$ and centre $(\mathrm{r}, 0)$.

$$
(x-r)^{2}+y^{2}=r^{2}
$$

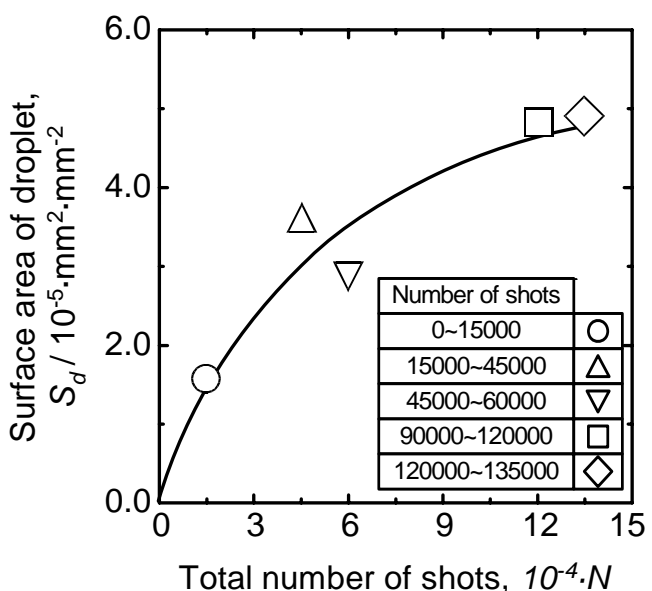

Fig. 7 Effect of total number of shot on surface area of droplet.

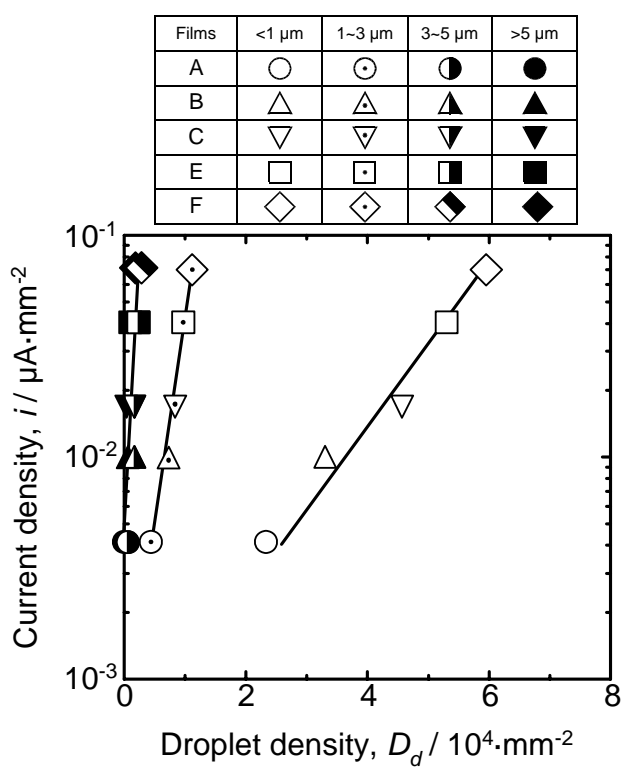

Fig. 8 Relationship between droplet density and passivation current density.

A spherical zone may be thought to be formed when an arc of the circle rotates around the $\mathrm{x}$ axis. For finding the area of the zone, we can use the formula of the entry area of surface of revolution.

$$
S_{1}=2 \pi \int_{a}^{b} y \sqrt{1+\left(\frac{d y}{d x}\right)^{2}} d x
$$

Let the ends of the arc correspond the values a and $b$ of the abscissa such that $b-a=h$ is the height of the spherical zone. In the formula, we must use the solved form of the equation of the circle.

$$
y=\sqrt{r x-x^{2}}
$$

The formula then yields following equation.

$$
\begin{aligned}
& S_{1}=2 \pi \int_{a}^{b} \sqrt{r x-x^{2}} \sqrt{1+\left(\frac{r-x}{\sqrt{r x-x^{2}}}\right)^{2}} d x \\
& =2 \pi \int_{a}^{b} r d x=2 \pi r(b-a)
\end{aligned}
$$




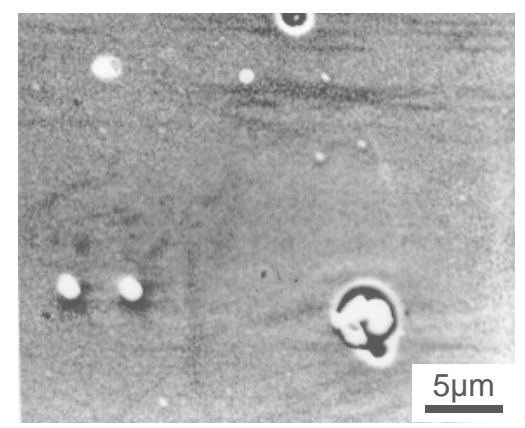

Fig. 9 Pitting corrosion on the boundaries between the film and droplet.

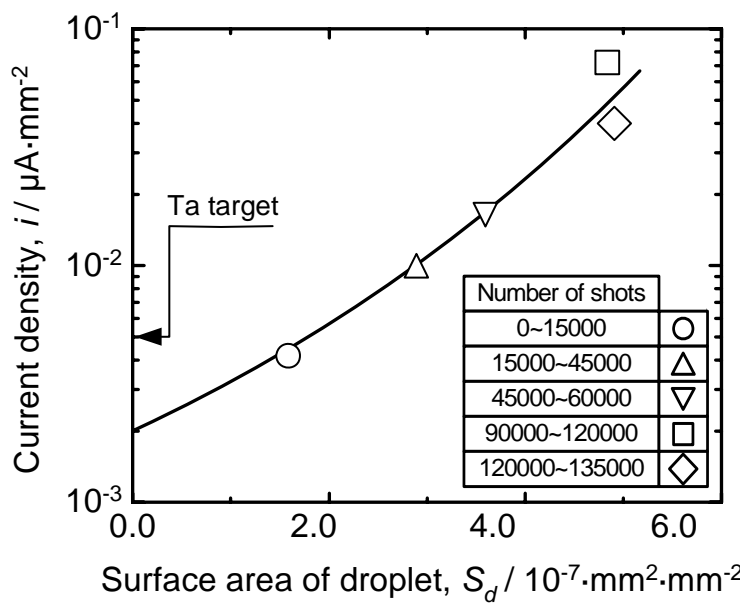

Fig. 10 Effect of surface area of droplets on current density corrosion.

film and droplets larger than $3 \mu \mathrm{m}$. However, for the case of droplets less than $1 \mu \mathrm{m}$, the corrosion rate was much lower.

Figure 10 shows the effect of the total surface area of droplets on the corrosion resistance. The current density is seen to increase with increasing $\mathrm{S}_{\mathrm{d}}$. Film A exhibits high corrosion resistance and had a passivation current density as low as that of the tantalum plate used as a target although the film thickness was only $1 \mu \mathrm{m}$. Droplets larger than the film thickness are related to the morphology of the target surface prior to deposition. Polishing the target surface before each PLD was found to decrease the density of such droplets and improve the corrosion resistance of the film.

It can be seen from Fig. 10 that the relationship between the current density and $S_{d}$ is not linear. Droplets with diameters larger than the film thickness had a much more significant influence on the corrosion resistance. Such droplets can also form short circuits to the substrate. This is not the case for droplets with diameters less than the film thickness. Therefore, control of the droplet diameter is crucial to improve the corrosion resistance of such films.

\section{Conclusions}

In this work the influence of metal-rich droplets on the corrosion resistance of tantalum oxide films was studied. The numerical density of such droplets was found to increase with the number of laser shots, with a concurrent increase in the droplet diameter. This led to an increasingly rough surface morphology. It was found that changing the initial roughness of the target allowed the droplet density to be controlled. Significant corrosion occurred only at the boundaries of the film and droplets larger than the film thickness. In order to improve corrosion resistance, the number of droplets with such large diameters should therefore be reduced.

\section{Acknowledgments}

The authors would like to thank Dr. T. Ooie, Dr. T. Yano, Dr. M. Yoneda, and Dr. M. Katsumura of the National Institute of Advanced Industrial Science and Technology for their helpful suggestions during this work. 


\section{References}

[1] K.A. McKinley and N.P. Sandler, Thin Solid Films, 290-291 (1996) 440. (Journals)

[2] H. Shinriki, T. Kisu, S.-I. Kimura, Y. Nishioka, Y. Kawamoto and K. Mukai, IEEE Trans. Electron Devices, 37 (1990) 1939. (Journals)

[3] K.S. Tang, W.S. Lau and G.S. Samudra, IEEE Circuits and Devices Magazine, 13 (1997) 27. (Journals)

[4] R.M. Fleming, D.V. Lang, C.D.W. Jones, M.L. Steigerwald, D.W. Murphy, G.B. Alers, Y.-H. Wong, R.B. van Dover, J.R. Kwo and A.M. Sergent, J. Appl. Phys., 88 (2000) 850. (Journals)

[5] M. Kiyotoshi, K. Hieda, Y. Fukumizu, Y. Kohyama, T. Suzuki1, D. Matsunaga and K. Hashimoto, Jpn. J. Appl. Phys., 42 (2003) 1943. (Journals)

[6] W. Sugimoto, T. Kizaki, K. Yokoshima, Y. Murakami and Y. Takasu, Electrochem. Acta, 49 (2004) 313. (Journals)

[7] C. H. An and K. Sugimoto, J. Electrochem. Soc., 141 (1994) 853. (Journals)

[8] P.M. Natishan, E. McCafferty, P.R. Puckett and S. Michel, Corros. Sci., 38 (1996) 1043. (Journals)

[9] G.P. Vercesi, J. Rolewicz, C.Comninellis and J.Hinden, Thermochem Acta, 176 (1991) 31. (Journals)
[10] A.K. Chu, M.J. Chuang, K.Y. Hsieh, H.L. Huang, Y.C. $\mathrm{Yu}, \mathrm{C} . \mathrm{W}$. Wang and E.K. Lin, Journal of Electronic Materials, 28 (1999) 1457. (Journals)

[11]C.M. Sulyma and D. Roy, Corros. Sci., 52 (2010) 3086. (Journals)

[12] T. Hino, M. Nishida, T. Araki, Surface \& Coatings Technology, 149 (2002) 1. (Journals)

[13] T. Hino, M. Salim, M. Nishida, T. Araki, Applied Surface Science, 189 (2002) 1. (Journals)

[14] T. Hino, S. Mustofa, M. Nishida, T. Araki, Vacuum, 70 (2003) 47. (Journals)

[15] T. Venkatesan, X. D. Wu, R. Muenchausen, A. Pique, MRS BULLETIN February, (1992) 54. (Conference Proceedings)

[16] S. Fähler, M. Störmer and H.U. Krebs, Applied Surface Science, 109-110 (1997) 433. (Journals)

[17] J.H. Yoo, S.H. Jeong, X.L. Mao, R. Greif and R.E. Russo, Appl. Phys. Lett., 76 (2000) 783. (Journals)

[18]H. Dömer and O. Bostanjoglo, J. Appl. Phys., 94 (2003) 6280. (Journals)

[19] T. Szörényi, R. Stuck, F. Antoni and E. Fogarassy, Applied Surface Science, 247(2005) 45. (Journals)

[20]L. Cultrera, M.I. Zeifman and A. Perrone, Applied Surface Science, 253 (2007) 6322. (Journals)

(Received: October 18, 2010, Accepted: December 09, 2010) 